\title{
Society for Computers in Psychology
}

\section{Editorial}

This issue of Behavior Research Methods comprises, in part, articles based on presentations from the 37th Annual Meeting of the Society for Computers in Psychology (SCiP) held in Long Beach, California. SCiP is a society that brings together psychologists interested in the techniques and issues surrounding the use of computers in all facets of psychology. The annual meeting is held the day before the Psychonomic Society meeting at the same location. The conference still manages to maintain the vital element that is the major reason for the development of conferences: conversation. You can still discuss the issues with colleagues you know, as well as with colleagues you meet as a result of their presentations. Over the years, many ground-breaking techniques for the use of computers in psychological research and teaching have been presented first at this conference. These studies often later find their way into this journal, either as part of this special issue or as regular contributions. If you have an interest in the use of computers in psychology and are going to the Psychonomic Society's annual meeting, it would be worth arriving a day early to take in this important conference. In addition, if you are reading this journal, you should also consider attending the conference. The history of this journal and conference are tightly intertwined. For more information about SCiP, check out www.scip.ws.

\section{The 2007 Annual Meeting}

The one-day conference was held at the Hyatt Regency in Long Beach, California, on November 15,2006 . The program included a wide range of presentations in seven paper sessions and one poster session. The paper topics included Web-based research, computer modeling, quantitative methods, discourse methods, educational methods, and multimodal expert systems. The program chairs for the 2007 meeting were Roman Taraban and Kim-Phuong L. Vu. Roman Taraban delivered the Presidential Address, "An Impoverished Machine: Challenges to Learning and the Role of Technology." The 2007 winner of the Castellan student paper award was Richard N. Landers, of the University of Minnesota, with a paper titled "TREND: A Tool for Rapid Online Research Literature Analysis and Quantification." Versions of both of these papers are included in this issue.

The SCiP articles in this issue were contributed to $B R M$ and were reviewed by the journal's consulting editors, members of the conference steering committee, and ad hoc reviewers who have expertise in each paper's subject area. I thank all of the reviewers for their important contribution to the quality of these articles.

At this meeting, the officers for the next year were announced. Gary Bradshaw, of Mississippi State University, assumes the presidency; Xiangen $\mathrm{Hu}$, from the University of Memphis, is president-elect; and Kay Livesay, of Linfield College, is the secretary-treasurer. The steering committee for 2008 consists of Curt Burgess, University of California; Katja Wiemer-Hastings, Northern Illinois University; Michael N. Jones, Indiana University; Ping Li, University of Richmond; Joseph P. Magliano, Northern Illinois University; Ulf-Dietrich Reips, Universität Zürich; Michael Schulte-Mecklenbeck, University of Bergen; Kim-Phuong L. Vu, California State University; and David A. Waller, Miami University.

\section{The 2008 Annual Meeting}

The 38th Annual Meeting of SCiP will be held at the Chicago Hilton Hotel, on Thursday, November 13, 2008, just before the annual meeting of the Psychonomic Society. The Call for Papers may be found elsewhere in this issue, as well as at www.scip.ws. Presentations geared for all levels of listeners are appropriate, including introductory tutorials, new ways of teaching or collecting data, and technical information for researchers and programmers. Individuals interested in suggesting a 
topic for a symposium or in submitting a paper for the 2008 meeting are urged to contact the program chair, Kim-Phuong L. Vu, with questions or comments.

Kim-Phuong L. Vu

Department of Psychology

California State University

1250 Bellflower Blvd.

Long Beach, CA 90840

Tel. (562) 985-5021

E-mail:kvu8@csulb.edu

As in the past, papers presented at the SCiP conference may be considered for the issue of Behavior Research Methods to be published the following August. The deadline for submitting manuscripts online (at mc.manuscriptcentral.com/psychonomic/brmic) is November 10, 2008. If you have any questions, please contact me, the proceedings editor, at krantzj@hanover.edu.

\section{About the Society for Computers in Psychology}

Membership in SCiP and participation at the meeting are open to all who are interested in the uses of computers in psychological research, teaching, and applications. Information about joining SCiP or participating in its meeting may be obtained from the society's Web page (www.scip.ws) or from its secretary-treasurer, Kay Livesay (klivesa@linfield.edu). Students are welcome to join the society and to participate in its meetings. The John Castellan award is given for the best student paper presented at the conference.

John H. Krantz

Hanover College 